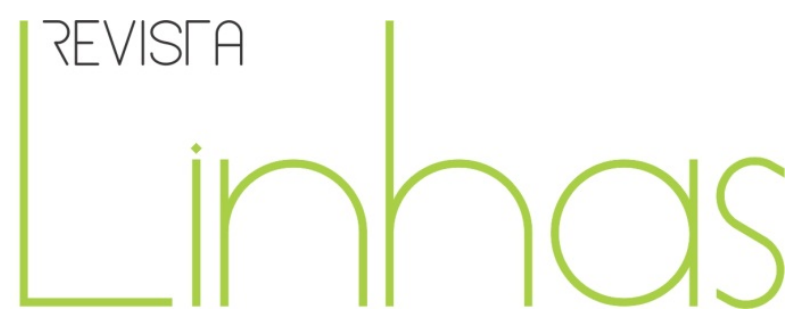

\title{
As desigualdades no Brasil e em outros Estados emergentes. Comparações com um grupo de controle ${ }^{1}$
}

\begin{abstract}
Resumo
Neste artigo procuramos evidenciar o papel excessivo e nocivo que as desigualdades exercem quando se trata de um desenvolvimento que respeite, ainda que minimamente, os humanos e seu meio ambiente, na totalidade do planeta. $O$ desafio a que nos propusemos consistiu em analisar, comparativamente, países emergentes que integram o BRICS (África do Sul, Brasil, China, Índia e Rússia) com um grupo de controle, abrangendo Alemanha, Canadá, Cuba, Estados Unidos e Japão (quatro deles pertencentes ao G7). Para tanto, tomamos como referência um conjunto de dados relativos à renda, saúde e educação, coletados pelo Programa das Nações Unidas para o Desenvolvimento (PNUD), particularmente 0 índice de desenvolvimento humano (IDH) ajustado pelo prêmio Nobel de Economia Amartya Sen. Nossas conclusões indicaram que, hoje, mais do que no momento em que fora elaborada, há meio século, as teorias da herança cultural e da reprodução social de Pierre Bourdieu e Jean-Claude Passeron (1964 e 1970) continuam pertinentes e assim o serão enquanto as desigualdades não forem combatidas.
\end{abstract}

Palavras-chave: Desenvolvimento humano; renda; saúde; educação; herança cultural e reprodução social.

\author{
Gabriel Langouët \\ Doutor em Sociologia pela \\ Universidade Descartes - Paris V \\ langouetgabriel@yahoo.fr
}

\begin{abstract}
Para citar este artigo:
LANGOUËT, Gabriel. As desigualdades no Brasil e em outros Estados emergentes. Comparações com um grupo de controle. Revista Linhas. Florianópolis, v. 15, n. 29, p. 137-161, jul./dez. 2014. Título original: Les inegalites au Bresil et dans d'autres etats emergentes. Comparaisons avec um groupe temoin. Traduzido por Fernando Coelho, com revisão técnica de Ione Ribeiro Valle.
\end{abstract}

DOI: $10.5965 / 1984723815292014137$

http://dx.doi.org/10.5965/1984723815292014137

\footnotetext{
${ }^{1}$ Artigo traduzido por Fernando Coelho - zeffiretto@gmail.com, com revisão técnica de lone Ribeiro Valle ione.valle@ufsc.br.
} 


\title{
Inequalities in Brazil and in other emerging States. Comparisons with a control group
}

\begin{abstract}
In this article we seek to highlight the excessive and harmful role that inequalities exert when it comes to a development that should respect, although minimally, humans and their environment, in the totality of the planet. The challenge we set ourselves was to analyze comparatively emerging countries that make up the BRICS (South Africa, Brazil, China, India and Russia) with a control group, embracing Germany, Canada, Cuba, United States and Japan (four of them belonging to the $\mathrm{G} 7$ ). For that, we take as reference a set of data concerning income, health and education, collected by the United Nations Development Program (UNDP), particularly the human development index (HDI) adjusted by the Nobel Prize in Economics Amartya Sen. Our conclusions indicated that, today, more than at the time they were developed, half a century ago, the theories of cultural heritage and social reproduction of Pierre Bourdieu and Jean-Claude Passeron (1964 and 1970) are still relevant and so they will be while inequalities are not undone.
\end{abstract}

Keywords: Human Development; Income; Health; Education; Cultural Inheritance and Social Reproduction. 


\section{Preâmbulo}

Este artigo constitui a continuação de duas obras (LANGOUËT, 2011 e 2014), que se propuseram a pôr em evidência o papel excessivo e nocivo que exercem as desigualdades quando se vislumbra um desenvolvimento humano menos indecente, que respeite, ainda que minimamente, o meio ambiente, na totalidade do planeta. Lembremos alguns aspectos essenciais que esclarecem o procedimento adotado neste novo estudo.

O primeiro se propôs, no nível da quase totalidade dos Estados do planeta - 182 de 192 foram observados -, um estudo aprofundado sobre a maneira pela qual essas desigualdades, tanto entre os Estados quanto no interior deles, se elaboram, se entrecruzam e se sobrepõem ou se multiplicam, especialmente em função dos três principais setores que as engendram: indicadores econômicos estimados especialmente a partir da renda nacional bruta por habitante (RNB/h); indicadores de saúde focados sobretudo na expectativa de vida no nascimento; indicadores de educação que resumem por um lado as taxas médias de alfabetização dos adultos e, por outro, o número médio de anos de expectativa de escolarização dos jovens. Mas também outros indicadores aos quais voltaremos. Uma ilustração da complexidade dos fatos sociais que, como sublinha Edgar Morin, faz com que as causas, por sua vez, tornem-se efeitos, e reciprocamente.

A primeira condição para a realização deste trabalho repousava sobre a obtenção de dados confiáveis e homogêneos. Daí nossa opção por dados brutos coletados pelo Programa das Nações Unidas para o Desenvolvimento (PNUD), essencialmente em 2008, e pela utilização dos poderosos índices que as equipes do PNUD estabeleceram, sobretudo o índice de desenvolvimento humano ajustado pelo prêmio Nobel de Economia Amartya Sen, além dos indicadores de repartição das rendas nas populações, do coeficiente de Gini e das diferenças entre os decis extremos. Quer seja entre os Estados, quer entre as populações de um mesmo Estado, a medida das desigualdades pôs em evidência diferenças de uma amplitude por vezes totalmente desmedida e intolerável: “demais, é demais!". Lembremos alguns resultados. 
- Renda nacional anual bruta por habitante: US\$140 em Burundi, US\$ 87.000 na Noruega.

- $\quad$ Expectativa de vida: 45 anos no Afeganistão, 83 anos no Japão.

- Mortalidade infantil: 150\% no Afeganistão, 3\% na Suécia.

- $\quad$ Número de filhos por mulher: 7 no Níger, menos de 2 na quase totalidade dos Estados mais ricos.

- Alfabetização: $26 \%$ dos adultos e $18 \%$ das mulheres, no Mali.

- Escolaridade primária concluída: menos de uma criança entre 3, e meninas ainda menos, termina sua escolaridade primária no Chade ou na República Centro-Africana. Acesso ao ensino superior: 90\% na Finlândia.

- Relação de repartição da renda entre os $10 \%$ mais ricos e os $10 \%$ mais pobres: Suécia, 6; Namíbia: $130 \ldots$

Nossa segunda obra dedicou-se ao estudo das desigualdades no conjunto dos Estados da União Europeia (UE), na zona do Euro ou fora dela, em comparação com uma amostra de 10 outros Estados do planeta (entre os quais o Brasil). De acordo com nossa principal hipótese, derivada das observações realizadas quando da preparação da obra precedente, a UE, tanto entre os seus Estados quanto no interior deles, era marcada por desigualdades ainda maiores, mas nada semelhante às desigualdades constatadas no nível planetário. Decorre daí um duplo objetivo: primeiramente, procurar conhecer melhor essa realidade; e sobretudo mostrar que essas proximidades, mesmo relativas, poderiam constituir um trampolim para novos avanços ${ }^{2}$.

A passagem pelo PNUD impôs-se novamente, tanto no que concerne aos dados que ele agrupa e atualiza permanentemente (dados de 2011, desta vez), quanto pelo conceito de desenvolvimento humano que ele desenvolve e enriquece. Ademais, entre 2008 e 2011, ele aprofundou suas ferramentas de análise do desenvolvimento humano (acrescentando notadamente um índice “ajustado às desigualdades”) e elaborou um excelente índice das desigualdades de gênero. Enfim, dispúnhamos de um material de qualidade e cuja consulta é extraordinariamente fácil.

\footnotetext{
${ }^{2}$ Aconselhamos a leitura, mesmo que rápida, desta obra (LANGOUËT, ${ }^{2014)}$, pois ela prepara, quanto aos conteúdos e metodologia, para a deste artigo.
} 
A recepção que esta obra recebeu, apesar do clima político pouco propício (o entusiasmo dos europeus pela UE continua modesto), faz pensar que nosso duplo objetivo, de informação e de proposição, foi atingido:

- A UE apresenta algumas desigualdades, mas desigualdades assaz moderadas, sobretudo em relação às observadas no grupo de controle;

- Nas três dimensões do desenvolvimento humano - renda, vida e saúde, educação -, a homogeneidade domina, facilitando aproximações, ainda que as desigualdades segundo o gênero permaneçam frequentemente acentuadas. E as diferenças se mostram menores, sobretudo em termos de renda, do que as observadas entre a República Federal Alemã (RFA) e a República Democrática Alemã (RDA) antes da reunificação;

- Outros exemplos, especialmente os da Finlândia ou da Suécia, mas também o da República Tcheca, em particular em educação, mostram que a redução das desigualdades, sob todas as formas, não foi um freio ao desenvolvimento. "E se se ousasse?", escolhemos, desta vez, como subtítulo.

\section{Introdução}

As pesquisas que mencionamos brevemente no preâmbulo mostram que o desafio maior do século XXI, para a totalidade dos seres humanos, assim como para o nosso planeta, que vai ao encalço da sua autodestruição, seria o do progresso do desenvolvimento humano (quadro 1), para todos e, no mínimo, para o maior número; mas elas também evidenciam que esse objetivo não pode ser atingido sem uma nítida redução das desigualdades mais insuportáveis, tanto entre os Estados, quanto entre as populações dos Estados. A ideia segundo a qual seria suficiente produzir mais para que a riqueza, por si só e sem imposições, fosse repartida, é uma ideia falsa, totalmente contestada pelos próprios fatos e pela última crise global. Ela é, contudo, repetida pelos defensores do neoliberalismo, mas também firmemente combatida por grandes economistas de notoriedade internacional, que demonstram a necessidade de regulações, em particular no que concerne à grande finança e aos paraísos fiscais. 
Ademais, num contexto globalizado, um Estado sozinho tem pouco peso, salvo se ele está entre os muito "grandes", pois está sujeito a fortes imposições internacionais; e o encerramento nas fronteiras nacionais e numa economia fechada é sem dúvida um engano: é sobretudo na direção de uma evolução profunda da globalização que é necessário caminhar. E é no prolongamento dos trabalhos anteriores, e no mesmo contexto, que se insere a presente contribuição, concentrada nos Estados ditos emergentes.

O conceito de emergência econômica data do início dos anos 1980. Os economistas concordam, em sua maioria, com o fato de que os habitantes dos países emergentes dispõem de rendas intermediárias, compreendidas entre 10\% e $75 \%$ da renda por habitante da União Europeia, e experimentam um crescimento econômico superior ao crescimento médio mundial; esses países devem, além disso, desenvolver uma política econômica de abertura e, portanto, desempenhar um papel significativo nas trocas mundiais, daí a importância das exportações. Na verdade, são excluídos sobretudo os Estados muito pobres e/ou de populações reduzidas. No começo dos anos 2010, cerca de 60 Estados (de quase 200), representando perto da metade da riqueza anual criada no planeta e dois terços da sua população, correspondiam a esses critérios. A lista é evidentemente provisória, enquanto alguns Estados foram muito rapidamente alcançando o grupo dos países desenvolvidos, outros, ao contrário, foram perdendo esse status intermediário, sobretudo se o seu nível de crescimento baixou muito.

Tendo em vista o agrupamento dos Estados mais ricos (o G7, por exemplo ${ }^{3}$ ), e visando melhor influir nas políticas econômicas e financeiras conduzidas no contexto da globalização, Estados emergentes também se aproximaram. Esse é principalmente o caso do BRICS ${ }^{4}$. Para balizar a discussão, o planeta conta atualmente com cerca de 7 bilhões de humanos, eles deverão ser 10 bilhões por volta de 2050. Hoje, os 5 Estados emergentes agrupados nos BRICS reúnem, por si sós, cerca de 3 bilhões de seres humanos, ou seja, cerca de $40 \%$ dos 7 bilhões; eles contribuíram com 27\% do PIB mundial em 2011, mas sua contribuição deveria, segundo estimativas, chegar a 40\% a partir de 2025. O G7, por

\footnotetext{
${ }^{3}$ Alemanha, Canadá, Estados Unidos, França, Itália, Japão e Reino Unido.

${ }^{4}$ Brasil, Rússia, Índia, China e África do Sul.
} 
exemplo, agrupa Estados desenvolvidos, que, no total, contam com pouco mais de 700 milhões, ou seja, pouco mais de 10\% da população mundial; mas, em 2012, sua contribuição para o PIB mundial estava na ordem de $47 \% 5$.

Como fizemos a propósito da União Europeia, pareceu indispensável constituir um grupo de controle composto por Estados que podiam ser comparados com os que integram o BRICS.

Como o BRICS, esse grupo é composto de cinco Estados e, sobretudo, de Estados desenvolvidos, tão representativos quanto possível das grandes potências econômicas do planeta ${ }^{6}$. Quatro foram escolhidos entre os Estados do G7, dos quais dois sem nenhuma hesitação: os Estados Unidos, principal potência econômica mundial, e o Japão, terceira depois da China e principal potência da Ásia; o terceiro Estado escolhido é a Alemanha, quarta potência mundial e país mais populoso da UE. O quarto, o Canadá, pode ser mais amplamente discutido: ele não é, diga-se, senão a oitava potência econômica mundial, além disso, sua população é pequena em relação aos outros; mas suas diferenças com os Estados Unidos merecem observação. O quinto, Cuba, cuja renda por habitante se situa entre a da China e a da Índia, foi selecionado porque figuraria entre os grandes emergentes se tivesse o tamanho das suas populações; e seus resultados, tanto nas áreas da vida e da saúde quanto na da educação, se parecem, se comparadas.

\begin{tabular}{ll}
\hline Estados Emergentes (BRICS) & Grupo de Controle \\
\hline África do Sul & Alemanha \\
Brasil & Canadá \\
China & Cuba \\
Índia & Estados Unidos \\
Rússia & Japão \\
\hline & Quadro 1. Os 2 grupos de Estados \\
\hline
\end{tabular}

Esta pesquisa se apoia mais uma vez em dados estatísticos de qualidade regularmente reunidos ou elaborados pelo PNUD e, mais particularmente, nos que foram

\footnotetext{
${ }^{5}$ Todos os peritos sérios consideram que o crescimento, se continuar nesse ritmo sem recorrer às energias renováveis e à recuperação das matérias primas, levará rapidamente ao esgotamento dos recursos planetários.

${ }^{6}$ Não são os mais ricos em termos de rendas por habitante, e os Estados mais ricos têm frequentemente populações modestas: Luxemburgo, Noruega, Catar e outros.
} 
objeto do último Relatório publicado em 2013. Nele, os dados mais recentes datam de 2011, assim como as valiosas ferramentas e índices levantados por essa equipe.

\section{Rendas, saúde, educação. Variações segundo os Estados}

O PNUD utiliza indicadores ou séries de indicadores que representam essas três áreas e que compõem, cada uma em um terço, a determinação do índice de desenvolvimento humano $(\text { IDH })^{7}$.

1 - As rendas (quadro 2)

\begin{tabular}{|c|c|c|c|c|c|c|}
\hline & \multicolumn{3}{|c|}{$\mathrm{RNB} / \mathrm{h}^{1}$} & \multicolumn{3}{|c|}{ População } \\
\hline & Dólares & Posição ${ }^{2}$ & Decil & Milhões & Acúmulo & $\%$ urbanos \\
\hline \multicolumn{7}{|c|}{ Estados emergentes (BRICS) } \\
\hline Rússia & 14561 & 53 & $9^{\circ}$ & 147,8 & - & 73,2 \\
\hline Brasil & 10162 & 77 & $8^{\circ}$ & 196,7 & 344,5 & 86,9 \\
\hline África do Sul & 9469 & 79 & $8^{e}$ & 50,5 & 395,0 & 62,2 \\
\hline China & 7476 & 94 & $5^{\circ}$ e $6^{\circ}$ & 1347,6 & 1742,6 & 47,8 \\
\hline Índia & 3468 & 124 & $3^{\circ}$ e $4^{\circ}$ & 1241,5 & 2984,1 & 30,3 \\
\hline \multicolumn{7}{|c|}{ Grupo de controle } \\
\hline Estados Unidos & 43017 & 10 & $10^{\circ}$ & 313,0 & - & 87,6 \\
\hline Canadá & 35166 & 16 & $10^{\circ}$ & 34,2 & 347,2 & 80,7 \\
\hline Alemanha & 34854 & 17 & $10^{\circ}$ & 82,2 & 429,4 & 74,0 \\
\hline Japão & 32295 & 23 & $10^{\circ}$ & 126,5 & 555,9 & 67,0 \\
\hline Cuba & 5416 & 103 & $5^{\circ}$ & 11,3 & 567,2 & 75,2 \\
\hline Mundo - 187 Estados & 10082 & - & - & - & - & 50,8 \\
\hline \multicolumn{7}{|c|}{$\begin{array}{l}{ }^{1} \text { Renda nacional bruta por habitante. US\$ PPA, valor de } 2005 . \\
{ }^{2} \text { Posição mundial, de } 187 .\end{array}$} \\
\hline
\end{tabular}

O principal indicador que influi sozinho no índice é a renda nacional bruta por habitante (RNB/h). Ele é revisto anualmente e constitui um elemento confiável do nível de

\footnotetext{
${ }^{7}$ Todos os dados são arredondados, a partir dos dados de origem (dados de 2011).
} 
vida médio das populações ${ }^{8}$. Acrescentou-se a ele por vezes outros indicadores, por exemplo, a taxa de urbanização.

Entre os cinco Estados do BRICS, a RNB/h evolui de US\$ 14.600 na Rússia ( $53^{\text {a }}$ posição mundial, 148 milhões de habitantes - grupo dos Estados muito ricos do $9^{\circ}$ decil) a US\$ 3.500 na Índia (124 posição, 1,24 bilhões - Estado pobre dos $3^{\circ}$ e $4^{\circ}$ decis). Os três outros Estados se situam em posição mais intermediária: Brasil, US\$ 10.200 (197 milhões) e África do Sul, US\$ 9.500 (50,5 milhões), quase iguais nas posições ( $77^{\mathrm{a}}$ e $79^{\mathrm{a}}$ ), no nível da média mundial (US\$10.100) e ocupando o $8^{\circ}$ decil, o dos Estados ricos; China, enfim, com US\$ 7.500 (1,35 bilhões), no nível mediano, separando a humanidade do planeta em duas partes iguais, uma mais pobre e outra mais rica. No total e quanto às rendas, trata-se de um grupo de Estados muito heterogêneo, o que se confirma quando se observa o grau de urbanização. Dois Estados permanecem muito fragilmente urbanizados, a China com 48\% e a Índia com 30\%; os três outros o são majoritariamente: $62 \%$ na África do Sul, $73 \%$ na Rússia e $87 \%$ no Brasil.

A homogeneidade das rendas, com exceção de Cuba, é maior no grupo de controle, uma vez que contemplamos quatro Estados do $\mathrm{G} 7$, todos do $10^{\circ}$ decil e extremamente ricos. Lembremos, contudo, que os Estados Unidos, US\$ 43.000 (10 posição, 313 milhões de habitantes), afastando-se claramente do grupo compacto dos três outros: Canadá, US\$35.200 (16 posição, 34 milhões de habitantes); Alemanha, US\$ 34.900 (17 posição, 82 milhões); Japão, US\$ 32.300 (23 $3^{\text {a }}$ posição, 126,5 milhões). Cuba, com 11 milhões de habitantes, dispõe de uma RNB/h bem mais modesta - US\$ 5.400, 8 vezes menos que os Estados Unidos, o que o coloca na $103^{\mathrm{a}}$ posição, nos $5^{\circ}$ e $6^{\circ}$ decis, entre China e Índia. A homogeneidade relativa às taxas de urbanização é muito forte, e sempre igual ou superior aos dois terços, inclusive em Cuba: não há muitas regiões não urbanizadas, como na China ou, principalmente, na Índia.

\footnotetext{
${ }^{8}$ O Produto Interno Bruto (PIB) define a riqueza anual globalmente produzida.
} 
2 - A saúde (quadro $3^{9}$ )

A expectativa de vida no nascimento constitui o primeiro indicador de vida e saúde da população de um Estado. Resume, de fato, todos os outros e evolui em função das suas respectivas evoluções: por exemplo, entre os fatores de aumento da expectativa de vida no nascimento, o primeiro diz respeito à diminuição da mortalidade infantil.

O PNUD compreendeu-o bem, privilegiando este indicador para representar a área vida e saúde na determinação do IDH. Contudo, ele utiliza outros, para completar a informação: por exemplo, a expectativa de vida relacionada à saúde ${ }^{10}$, as taxas de não vacinação das populações (difteria, coqueluche e tétano, de um lado, rubéola de outro), as de mortalidade das crianças de menos de 5 anos e as de mortalidade dos adultos, homens ou mulheres, antes dos 60 anos, assim como a parte do PIB reservada às despesas públicas com saúde. Esses são os indicadores que analisamos sistematicamente. Poderíamos ter acrescido outros, por exemplo, o número médio de nascimentos por mulher ou a taxa de mortalidade infantil antes de um ano, mas eles nos parecem menos essenciais se comparados aos Estados e populações escolhidos.

\begin{tabular}{|c|c|c|c|c|c|c|c|c|}
\hline & \multirow{2}{*}{$\mathbf{E V}^{1}$} & \multirow{2}{*}{$E V / S^{2}$} & \multicolumn{2}{|c|}{ Vacinações ${ }^{3}$} & \multirow{2}{*}{$\begin{array}{l}\text { MI }(>5 \\
\text { anos) }\end{array}$} & \multicolumn{2}{|c|}{ MA $(15-60)^{5}$} & \multirow{2}{*}{$\begin{array}{c}\text { Desp. } \\
\text { Saúde } \\
(\% \mathrm{PIB})^{6}\end{array}$} \\
\hline & & & & & & $\mathbf{F}$ & H & \\
\hline \multicolumn{9}{|c|}{ Estas Emergentes (BRICS) } \\
\hline Rússia & 68,8 & 60 & 2 & 2 & 12 & 144 & 391 & 3,5 \\
\hline Brasil & 73,5 & 64 & 1 & 1 & 21 & 102 & 205 & 3,8 \\
\hline África do Sul & 52,8 & 48 & 31 & 38 & 62 & 479 & 521 & 4,0 \\
\hline China & 73,5 & 66 & 3 & 6 & 19 & 87 & 142 & 2,7 \\
\hline Índia & 65,4 & 56 & 34 & 29 & 66 & 169 & 250 & 1,3 \\
\hline \multicolumn{9}{|c|}{ Grupo de Controle } \\
\hline Estados Unidos & 78,5 & 70 & 5 & 8 & 8 & 78 & 134 & 8,4 \\
\hline Canadá & 81,0 & 73 & 20 & 7 & 6 & 53 & 87 & 8,1 \\
\hline
\end{tabular}

\footnotetext{
${ }^{9}$ Neste quadro figuram, toda vez que são conhecidos, os dados mundiais médios. Uma diretriz essencial para a leitura dos outros.

${ }^{10}$ Este indicador estima o número de anos em má saúde (doenças ou acidentes bem definidos). A expectativa de vida relacionada à saúde é portanto a diferença entre a expectativa da vida e este número de anos.
} 


\begin{tabular}{llllllllr}
\hline Alemanha & 80,4 & 73 & 7 & 4 & 4 & 53 & 99 & 9,0 \\
Japão & 83,4 & 76 & 2 & 6 & 3 & 42 & 86 & 7,8 \\
Cuba & $\mathbf{7 9 , 1}$ & 69 & 4 & 4 & 6 & 78 & 120 & 11,2 \\
\hline Mundo-187 Estados & $\mathbf{6 9 , 8}$ & $\mathbf{6 1}$ & $\mathbf{1 8}$ & $\mathbf{1 8}$ & $\mathbf{5 8}$ & $\mathbf{1 3 7}$ & $\mathbf{2 1 1}$ & - \\
\hline
\end{tabular}

${ }^{1} \mathrm{EV}$ : expectativa de vida no nascimento, em anos.

${ }^{2}$ EV: expectativa de vida relacionada à saúde, em anos.

${ }^{3}$ Porcentagem de crianças de um ano não vacinadas. DCT: difteria, coqueluche, tétano; R: rubéola.

${ }^{4} \mathrm{MI}$ : taxa de mortalidade infantil antes de 5 anos, sobre mil nascimentos vivos.

${ }^{5}$ MA: taxa de mortalidade antes dos 60 anos de adultos de 15 anos, homens ou mulheres, sobre 1000.

${ }^{6}$ Despesas públicas com saúde, parte do PIB (\%). Dados de 2009 mais ou menos.

Quadro 3. Indicadores de vida e saúde dos Estados emergentes e do grupo de controle

Observemos inicialmente os dados do grupo de controle. De todos ou quase todos os indicadores, os números são melhores do que as médias mundiais: um ganho de quase ou mais de dez anos na expectativa de vida e na expectativa de vida com boa saúde, taxas de vacinação e de mortalidade infantil com uma cifra, com exceção do caso do Canadá, taxas de mortalidade dos adultos baixas e inferiores às taxas mundiais (calculadas "por mil” e sobre 45 anos) e despesas com saúde que se aproximam ou ultrapassam 10\% do PIB. Certamente, todos os dados evoluem no mesmo sentido (salvo a vacinação DCT, para a qual seria necessário buscar explicação) e confirmam o valor de síntese do indicador expectativa de vida. Ora, ele varia em quase cinco anos, o que é considerável, entre os Estados Unidos, cujas rendas são mais elevadas, e o Japão, o menos rico dos quatro do $\mathrm{G} 7$, e aquele que se sai um pouco melhor que os outros, no conjunto de todos os critérios e, além disso, com uma parte do PIB ligeiramente inferior; inversamente, os Estados Unidos apresentam taxas de mortalidade infantil e de pessoas na faixa etária entre 15 e 60 anos mais elevadas: sem dúvida em razão de políticas de saúde diferentes. O Canadá e a Alemanha, próximos quanto à renda, se aproximam do Japão. Resta Cuba, que dedica mais de $11 \%$ do seu modesto PIB ao orçamento da saúde e iguala ou ultrapassa, com certeza ligeiramente mas em todos os critérios, os Estados Unidos, cuja RNB/h é oito vezes mais elevada, chegando perto da Alemanha e do Canadá, dois Estados extremamente ricos do $10^{\circ}$ decil.

A heterogeneidade é ainda maior no grupo dos Estados emergentes. A expectativa de vida varia de 53 anos na África do Sul a 73,5 anos no Brasil e na China, 
passado a 65 anos na Índia e a 69 anos, perto da média mundial, na Rússia. As permanências de expectativas de vida com boa saúde estão em muito boa correspondência: permanências com "má saúde" reduzidas a 5 anos na África do Sul e de 7 a 9 anos nos outros. As políticas de vacinação que a $\mathrm{OMS}^{11}$ recomenda (menos de 5 de não vacinações) são aplicadas no Brasil, na China e na Rússia, mas a prevenção permanece muito insuficiente na Índia ou na África do Sul onde quase um terço ou mais das crianças não são vacinadas. As taxas de mortalidade infantil antes de 5 anos são de duas cifras em todo lugar: $12 \%$ na Rússia, ou seja, 4 vezes mais do que no Japão, uma taxa que, na UE, não aparece senão na Romênia, 21\% e 19\% no Brasil e, sobretudo, 64\% e 66\%, mais do que a média mundial, na África e na China. As taxas de mortalidade de pessoas na faixa etária entre 15 e 60 anos, sobretudo homens, permanecem muito elevadas: somente as da China, $9 \%$ entre as mulheres e $14 \%$ entre os homens, ou, mais extremas, as do Brasil, 10\% e 20\%, se comparam às dos Estados Unidos ou de Cuba; as da Rússia, que realizou progresso no que diz respeito à mortalidade infantil, permanecem elevadas para as mulheres (14\%) e muito elevadas para os homens (39\%); as da Índia, sobretudo para as mulheres (17\%), um pouco mais baixas para os homens (25\%), quase dobram em relação à China; enfim, as da África do Sul, $48 \%$ e 52\%, mais de 10 vezes que no Japão para as mulheres e 6 vezes para os homens, parecem inverossímeis. Certamente, as proporções do PIB, variando de 1,3\% (no país mais pobre) a 4\% (na África do Sul), são insuficientes para progressos significativos. Despesas com saúde representam de 3\% a 4\% do PIB nos países mais ricos, proporções que baixam bastante sobretudo na China, onde o orçamento saúde não representa mais que $2,7 \%$ do PIB, e mais ainda na Índia onde ela regride para $1,3 \%$ do seu PIB.

Definitivamente e para resumir, os 10 Estados dos dois grupos, em função da expectativa de vida, classificam-se em 5 níveis ${ }^{12}$.

- Expectativa muito elevada, 80 anos e mais: Canadá, Alemanha e Japão, três Estados extremamente ricos, todos do grupo de controle, apresentando resultados muito próximos de outros Estados comparáveis, da UE por exemplo.

\footnotetext{
${ }^{11}$ Organização Mundial da Saúde.

${ }^{12}$ Esta classificação retoma a que foi utilizada na pesquisa realizada sobre a UE.
} 
- Expectativa elevada, 74 a 79 anos: Estados Unidos, extremamente rico, Cuba, mediano, ambos do grupo de controle. O primeiro obtém resultados um pouco aquém do seu nível de renda, o segundo resultados muito além.

- Expectativa menos elevada, 68 a 73 anos: Rússia, muito rico, e Brasil, rico, ambos do grupo de controle, China, mediano e Estado emergente. Os resultados da Rússia permanecem um pouco aquém dos que se poderia esperar, os do Brasil no nível esperado e os da China um pouco além.

- Expectativa baixa, 60 a 67 anos: Índia, pobre. A pobreza é sem dúvida o fator principal de suas dificuldades.

- Expectativa muito baixa, 53 a 59 anos: África do Sul, Estado emergente rico. As rendas, muito próximas das do Brasil, não podem, sozinhas, explicar esses resultados. Outras causas deverão ser procuradas.

3 - A educação (quadro $4^{13}$ )

\begin{tabular}{|c|c|c|c|c|c|c|c|}
\hline & \multirow{3}{*}{$\mathrm{DME}^{1}$} & \multirow{3}{*}{ TAA $^{2}$} & \multirow{3}{*}{$\mathrm{DEE}^{3}$} & \multicolumn{3}{|c|}{ Taxa bruta escolarização ${ }^{4}$} & \multirow{3}{*}{$\begin{array}{l}\text { Desp. } \\
\text { Educ. } \\
\left(\% \text { PIB }^{5}\right.\end{array}$} \\
\hline & & & & & & & \\
\hline & & & & Prim. & Sec. & Sup. & \\
\hline \multicolumn{8}{|c|}{ Estados emergentes (BRICS) } \\
\hline Rússia & 9,8 & 99,6 & 14,1 & 96,8 & 84,8 & 77,2 & 4,4 \\
\hline Brasil & 7,2 & 90,0 & 13,8 & 127,5 & 100,8 & 34,4 & 5,7 \\
\hline África do Sul & 8,5 & 88,7 & 13,1 & 101,2 & 93,9 & - & 5,5 \\
\hline China & 7,5 & 94,0 & 11,6 & 112,7 & 78,2 & 24,5 & - \\
\hline Índia & 4,4 & 62,8 & 10,3 & 116,9 & 60,0 & 13,5 & 3,1 \\
\hline \multicolumn{8}{|c|}{ Grupo de controle } \\
\hline Estados Unidos & 12,6 & - & 16,0 & 98,2 & 93,6 & 85,9 & 5,4 \\
\hline Canadá & 12,1 & - & 16,0 & 98,4 & 102,2 & 62,3 & 4,8 \\
\hline Alemanha & 12,2 & - & 15,9 & 103,6 & 101,7 & & 4,6 \\
\hline Japão & 11,6 & - & 15,1 & 102,3 & 101,0 & 58,6 & 3,4 \\
\hline Cuba & 9,9 & 99,8 & 17,5 & 99,3 & 93,5 & 67,1 & 14,1 \\
\hline Mundo - 187 Estados & 7,4 & 80,9 & 11,3 & 106,9 & 68,4 & 27,6 & - \\
\hline \multicolumn{8}{|c|}{$\begin{array}{l}{ }^{1} \text { Duração média de escolarização das pessoas de } 25 \text { anos e mais, em número de anos. } \\
{ }^{2} \text { Taxa de alfabetização dos adultos de } 15 \text { anos e mais, último dado conhecido entre } 2005 \text { e } 2010 . \\
{ }^{3} \text { Duração esperada de escolarização, em número de anos, para as crianças em idade de entrar na escola }\end{array}$} \\
\hline
\end{tabular}

\footnotetext{
${ }^{13}$ Nesse quadro figuram, toda vez que são conhecidos, os dados mundiais médios. Eles são uma base essencial.
} 
no ano considerado.

4 Taxa bruta de escolarização: primária, secundária e superior, últimos dados conhecidos entre 2001 e 2010.

${ }^{5}$ Despesas públicas com educação, parcela do PIB (\%), dados em torno de 2009.

Quadro 4. Indicadores de educação dos Estados emergentes e dos do grupo de controle

A Organização das Nações Unidas considera que o desenvolvimento humano na área da educação somente pode se realizar se visar ao mesmo tempo jovens e adultos; o PNUD utilizou por muito tempo dois indicadores principais, um avaliando a taxa de alfabetização dos adultos, outro as taxas de frequência dos diversos segmentos do sistema educacional, do primário ao superior. Doravante, e esse é o caso para o período examinado aqui, ele utiliza durações médias de escolarização dos jovens e adultos. Para os adultos, ele considerou a duração média de escolarização (DME), em número de anos, realizada pelo conjunto da população com idade de 25 anos ou mais. Para os jovens em escolarização, trata-se da duração esperada de escolarização (DEE), portanto de prognóstico. DME e DEE compõem, em partes iguais, o cálculo do índice de desenvolvimento humano.

O PNUD utiliza outros indicadores conexos dentre os quais consideramos:

- As taxas de alfabetização dos adultos, que evidenciam uma forte concordância com as DME;

- As taxas brutas atuais de escolarização, do primário ao superior;

- Como para a área da vida e da saúde, as taxas de despesas públicas com educação.

No grupo de controle, nenhum dos quatro Estados extremamente ricos informa sobre as taxas de alfabetização dos adultos, e Cuba, Estado mediano, indica uma taxa muito próxima de 100\%: não há mais, ou praticamente não há analfabetismo neste grupo, ainda que perdure uma taxa de iletrados difícil de identificar. As DME confirmam aliás esse bom nível de educação dos adultos: muito elevado, em torno de 12 anos ou mais nos Estados Unidos, no Canadá, na Alemanha e no Japão, elevado em Cuba. Os dados relativos à matrícula no ensino primário (de 98\% nos EUA e no Canadá, mais de 100\% duplas matrículas - no Japão ou na Alemanha) mostram que ele está totalmente generalizado; a situação é um pouco diferente quando se trata do ensino secundário: 
tanto em Cuba quanto nos EUA, 6\% a 7\% dos jovens, parcela pequena mas não negligenciável, continua fora. Em contrapartida, e sobretudo nesses dois Estados, a matrícula nos ensinos superiores é muito elevada (mais de dois terços) nos EUA (86\%) e em Cuba (67\%), elevada (de um terço a menos de dois terços) no Canadá (62\%) e no Japão $(59 \%)^{14}$. As durações esperadas de escolarização dos jovens (DEE) dividem-se entre o nível elevado no qual se agrupam os quatro Estados extremamente ricos (Japão, 15 anos, Estados Unidos, Canadá e Alemanha, 16 anos) e o nível muito elevado no qual aparece apenas Cuba (17 anos) alcançando poucos Estados do planeta, notadamente Estados da Europa do Norte. A parcela do PIB dedicada às despesas com educação é um pouco menor no Japão (3\%), mais homogênea nos três outros Estados extremamente ricos e claramente mais elevada em Cuba (14\%).

No grupo dos Estados emergentes, a DME varia de 4 anos (DME baixa) na Índia, duração muito inferior à DME média de mais ou menos 7 anos, a 10 anos (DME elevada) na Rússia, valor equivalente ao de Cuba; ela é menos elevada ( 8,5 anos) na África do Sul e baixa no Brasil e na China (7 anos). As taxas de alfabetização correspondem a essas durações em 4 dos 5 casos: a máxima é observada na Rússia (praticamente 100\%) e a mínima na Índia (63\%); elas são mais intermediárias no Brasil (90\%) e na China (84\%), mas estão estagnadas na África do Sul $(89 \%)^{15}$. A situação parece difícil para a Índia, pois embora tenha generalizado o seu ensino primário, permanece atrasada quanto ao desenvolvimento do ensino secundário (60\%) e, sobretudo, do ensino superior (13,5\%): no conjunto das dimensões, ela figura na categoria baixa. A Rússia surpreende: tem certamente um potencial, sua DME, mas não conseguiu generalizar seu ensino secundário (85\%), e projeta sua DEE para 14 anos (categoria menos elevada), enquanto $77 \%$ dos seus jovens já acessam ao ensino superior. Os três outros Estados parecem procurar avançar: eles aumentam a DEE em relação à DME, em mais de $6 \%$ no Brasil e $4 \%$ a $5 \%$ na China e na África do Sul, e, ao mesmo tempo, generalizam o acesso ao ensino secundário (100\% no Brasil, $94 \%$ na África do Sul e $78 \%$ na China), apesar das desigualdades que apresentam e às quais voltaremos. As taxas de acesso ao ensino superior, 24,5\% para a China,

\footnotetext{
${ }^{14}$ Taxa não indicada pela Alemanha.

${ }^{15} \mathrm{O}$ que corresponde somente a uma distribuição das durações de maior variação.
} 
classificada no nível baixo e 34\% para o Brasil, classificado no nível menos elevado, parecem em concordância com esse desenvolvimento ${ }^{16}$.

Definitivamente, tendo em conta ao mesmo tempo a educação dos jovens e dos adultos, os 10 Estados dos dois grupos se dividem assim:

- $\quad$ Nível global muito elevado: Estados Unidos, extremamente rico, Cuba, mediano, grupo de controle. O primeiro obtém resultados que correspondem ao seu nível de renda, o segundo resultados muito além;

- $\quad$ Nível global elevado: Canadá, Alemanha e Japão, três Estados extremamente ricos do grupo de controle; Rússia, Estado emergente muito rico. Os três primeiros registram resultados um pouco aquém das suas rendas, o quarto resultados concordantes;

- Nível global menos elevado: dois Estados ricos do grupo emergente, África e Brasil. Resultados em razoável concordância com as rendas;

- Nível global baixo. A China, Estado mediano, se situa um pouco além de suas rendas, a Índia, pobre, em concordância com as suas.

4 - Rendas, saúde e educação

Essas três áreas, tomadas sucessivamente duas a duas, rendas e saúde por um lado, rendas e educação por outro, evidenciaram correlações bastante frequentes, mas também claras concordâncias. Levando ao mesmo tempo em conta as três áreas, pode-se estabelecer a seguinte classificação:

- Dois Estados do grupo dos países emergentes aparecem em grande concordância. O Brasil, Estado rico, obtém resultados de nível menos elevado, tanto no que concerne à saúde quanto à educação. A Índia, Estado pobre, apresenta resultados baixos;

- Seis Estados apresentam concordância mais atenuada, produzindo resultados um pouco diferentes, mas contudo vizinhos, segundo as áreas. Entre os Estados emergentes, a Rússia, muito rica, classificada no nível elevado na área educação, classifica-se somente no nível menos elevado na área saúde; inversamente, a China, Estado mediano, permanece

\footnotetext{
${ }^{16}$ Taxa não indicada pela África do Sul. Tendo-se em conta as outras informações fornecidas, ela é, como no Brasil, classificada no nível menos elevado.
} 
no nível baixo na área educação, mas atinge o nível menos elevado na da saúde. Do mesmo modo, no grupo de controle, entre os quatro Estados extremamente ricos, dois casos inversos são observados: os Estados Unidos, coerentemente com suas rendas, situa-se no nível mais elevado em educação, mas no nível elevado na área saúde; os três outros, Canadá, Alemanha e Japão invertem o esquema: resultados de nível muito elevado na área saúde, de nível elevado na área educação. Sem dúvida, escolhas políticas diferentes e investimentos financeiros, que seria interessante estudar;

- Dois Estados mostram discordâncias claramente acentuadas e que merecem ser observadas. A África do Sul, Estado rico, produz resultados de nível menos elevado na área educação (como o Brasil) em razoável concordância com suas rendas, mas resultados, sobretudo quanto à expectativa de vida, que ainda a colocam no nível muito baixo, dentre os Estados do planeta em maiores dificuldades, persistindo o peso de uma história durante a qual os homens, para retomar a bela expressão que o PNUD utiliza, não eram senão “insumos necessários ao aumento da produção”. Em compensação, o exemplo de Cuba mostra um sucesso surpreendente apesar das rendas medianas irrisórias, sucesso que o reúne aos Estados Unidos, tanto na área da saúde quanto na da educação.

Certamente, a renda é um meio, e um meio indispensável, observamos isso sobretudo em relação à Índia, que enfrenta sérias dificuldades de desenvolvimento. Todavia, mais do que a própria renda, é seu modo de utilização e de repartição no interior das populações que conta e, evidentemente, as políticas postas em prática voltadas às dimensões essenciais do desenvolvimento humano.

\section{Desigualdades e índices. Um passo em direção à conclusão}

Todos os dados apresentados nas páginas precedentes constituem bons indicadores do desenvolvimento humano. E eles apresentam, entre si, uma razoável coerência, pois permitem produzir um retrato de cada um dos Estados e, por conseguinte, comparações entre esses Estados ou com outros para os quais se 
pesquisaria os mesmos tipos de dados. Não posso senão encorajar o leitor a este procedimento; comparar, por exemplo, o seu país com outro ou com vários outros.

Um índice é geralmente um resumo, em forma quantificada, efetuado a partir de indicadores estimados pertinentes. É o caso dos índices produzidos pelo PNUD (2013), indicando precisamente o que ele resume e como resume.

O PNUD elaborou uma série de índices relativos ao desenvolvimento humano. Nós utilizaremos dois deles: o índice propriamente dito (IDH) e o índice ajustado às desigualdades (IDHD). Ele produziu, aliás, recentemente, um judicioso índice de desigualdade de gênero (IIG) que também apresentaremos. Enfim, utilizaremos o coeficiente de $\mathrm{Gini}^{17}$, que mede as desigualdades de distribuição das rendas. Esses índices estão agrupados no quadro 4. Veremos, assim, como se constroem e se sobrepõem as desigualdades de desenvolvimento humano experimentadas pelas populações desses Estados.

\begin{tabular}{|c|c|c|c|c|c|c|c|c|c|}
\hline & \multicolumn{2}{|c|}{$\begin{array}{l}\mathrm{IDH}^{1} \\
2011\end{array}$} & \multicolumn{2}{|c|}{$\begin{array}{l}\text { IDHD }^{2}(2011) \\
\text { ajustado }\end{array}$} & \multicolumn{2}{|c|}{$I I G^{3}$} & $\mathbf{R Q} \mathbf{R}^{4}$ & \multicolumn{2}{|c|}{ G Gini ${ }^{5}$} \\
\hline \multicolumn{10}{|c|}{ Estados emergentes (BRICS) } \\
\hline Rússia & .755 & 66 & .670 & 11,3 & $\cdot 338$ & 59 & - & $\cdot 310$ & 16 \\
\hline Brasil & .718 & 84 & .519 & 27,7 & .449 & 80 & 17,6 & .539 & - \\
\hline África do Sul & .619 & 123 & - & - & .490 & 94 & 20,2 & $\cdot 578$ & 33 \\
\hline China & .687 & 101 & .534 & 22,3 & .209 & 35 & 8,4 & .415 & 18 \\
\hline Índia & $\cdot 547$ & 134 & . 392 & 28,3 & .617 & 129 & 5,6 & $\cdot 325$ & - \\
\hline \multicolumn{10}{|c|}{ Grupo de controle } \\
\hline Estados Unidos & .910 & 4 & .771 & 15,3 & .288 & 47 & 8,5 & .408 & 16 \\
\hline Canadá & .908 & 6 & .829 & 8,7 & .140 & 20 & 5,5 & .326 & - \\
\hline Alemanha & .905 & 9 & .842 & 6,9 & .085 & 7 & 4,9 & $\cdot 330$ & - \\
\hline Japão & .901 & 12 & - & - & .123 & 14 & 3,4 & .249 & 4 \\
\hline Cuba & • 776 & 51 & - & - & .337 & 5 & - & - & - \\
\hline Mundo - 187 Estados & .682 & - & .525 & 23,0 & .492 & - & & & \\
\hline
\end{tabular}

${ }^{1}$ Índice de desenvolvimento humano. À esquerda, valor (entre o e 1); à direita, posição (dentre 187).

2 Índice de desenvolvimento humano ajustado às desigualdades. À esquerda, índice corrigido em função das desigualdades próprias do Estado considerado; à direita, porcentagem de correção em relação ao IDH.

3 Índice de desigualdade de gênero, dados de 2011. À esquerda, valor do índice (entre o e 1); à direita,

\footnotetext{
${ }^{17}$ Estes três índices foram utilizados em nosso último trabalho que se refere à UE (LANGOUËT, 2014).
} 
posição (dentre 146 Estados).

${ }^{4}$ Relações dos quintis de renda. Valor da relação entre o primeiro e o quinto.

${ }^{5}$ Coeficiente $G$ de Gini. À esquerda, valor (entre o e 1); à direita, valor da relação entre o primeiro e o décimo decil.

Quadro 5. Os índices de desigualdades. Estados emergentes e grupo de controle

1 - O desenvolvimento humano e seus índices

O conceito de desenvolvimento humano prioriza mais os fins que os meios de desenvolvimento e progresso. O verdadeiro objetivo do desenvolvimento deveria, com efeito, consistir em criar um ambiente propício a uma vida melhor em termos de existência, saúde e criatividade. (PNUD, 2011)

O IDH informa sobre a potencialidade dos Estados, a partir das três áreas observadas (renda, saúde e educação) e em parcelas iguais. O IDH define o que deveria realizar cada Estado, e os classifica em função desse score: entre os 10 Estados, os EUA apresenta o melhor potencial $(0,910)$, ocupando a posição 4 no âmbito mundial; a Índia é a última (posição 134), com um score de 0,547.

Levando em consideração as desigualdades levantadas pelo PNUD (a partir dos mesmos critérios para todos os Estados), este elabora o índice ajustado às desigualdades (IDHI), o índice real, sempre inferior ao IDH (não existe desigualdade perfeita), e calcula, em porcentagens, as perdas ligadas às desigualdades: enquanto os EUA perdeu 15\%, a Índia perdeu $28 \%$.

Essas perdas constituem um verdadeiro desperdício: 23\% em nível mundial, quase um quarto do bem mais precioso. No nosso corpus, são sobretudo poupados o Canadá, $9 \%$, e a Alemanha, $7 \%^{18}$; mas os Estados emergentes são as principais vítimas (perdas da ordem de $28 \%$ para o Brasil e, sem dúvida, para a África do Sul...), porque eles têm um número muito maior de pobres. O único meio de fazê-las regredir é diminuir as desigualdades, para reduzir a pobreza ou erradicá-la.

\footnotetext{
${ }^{18}$ No nível mundial, as perdas mínimas são de 4\%: Suécia e República Tcheca.
} 
2 - As desigualdades de gênero

O índice (IIG) é construído a partir de um modelo próximo compreendendo igualmente três áreas - saúde, autonomização e mercado do emprego -, cada um participando em um terço no cálculo do índice final. A escolha dos indicadores parece bastante representativa e pertinente: abrangendo a saúde, a taxa de mortalidade materna e a taxa de fecundação das adolescentes; a autonomização, com base nos níveis de instrução de homens-mulheres (secundário ou superior) ${ }^{19}$ e na proporção de mulheres e homens nas assembleias parlamentares; enfim, o acesso ao emprego, calculado a partir da proporção de mulheres e homens na população ativa ${ }^{20}$.

O melhor score é obtido pela Alemanha, com um índice de 0,085, muito próximo de 0 , e $7^{\mathrm{a}}$ posição mundial: existem poucos países nos quais as desigualdades de gênero praticamente desapareceram; inversamente, elas são muito importantes na Índia $(0,617)$ ocupando a $129^{\mathrm{a}}$ posição. Elas permanecem baixas no Canadá e no Japão, médias na China, elevadas nos Estados Unidos, em Cuba e na Rússia, muito elevadas na África do Sul e no Brasil.

Mas, sozinhos, esses índices não bastam para qualificar essas desigualdades. É necessário observar a maneira como elas se constroem e os resultados segundo os diversos indicadores. Certamente, dois índices muito diversos põem em evidência nítidas diferenças de grau no que concerne às desigualdades de gênero: por exemplo, os Estados Unidos são menos desiguais que a Rússia; mas a observação dos indicadores por si evidencia que essa diferença está essencialmente ligada à distribuição do emprego, menos desigual nos Estados Unidos do que na Rússia. Sobretudo, a igualdade ou a proximidade dos índices (aqui, Canadá e Japão) pode mascarar, por compensação, diferenças opostas: esses dois Estados são igualitários, mas o Japão, mais igualitário que o Canadá no que diz respeito à saúde, é, em contrapartida, muito menos em relação ao acesso ao emprego. Um belo exemplo das necessárias complementaridades entre qualitativo e quantitativo.

\footnotetext{
${ }^{19}$ As situações são por vezes favoráveis às mulheres.

${ }^{20}$ O leitor interessado nesta análise pode consultar o nosso último trabalho, publicado em 2014, no qual um capítulo é dedicado a essas desigualdades e a esses Estados.
} 
Essas desigualdades, em muitos países, permanecem muito grandes e até mesmo crescem, sobretudo em períodos de crise e de desemprego e quando a pobreza aumenta. E elas são sempre desigualdades sobrepostas em relação às outras desigualdades: elas aparecem, por exemplo, especialmente nos países pobres, fortemente correlacionadas às perdas de desenvolvimento humano.

3 - As desigualdades de divisão de renda

O coeficiente de $\mathrm{Gini}^{21}$ é um ótimo índice. O princípio é simples: consiste em dividir as rendas em frações populacionais, frequentemente de 10\% (decimal), dos mais pobres aos mais ricos, e avaliar a evolução das rendas segundo essas frações; sendo perfeita a igualdade, cada fração recebe a mesma parte, sendo perfeita a desigualdade, os nove primeiros não recebem nada porque a décima fração recebe tudo. Em teoria, ele varia de o (igualdade máxima) a 1 (desigualdade máxima); na prática, entre os Estados do planeta, ele varia entre 0,2 (desigualdades muito pequenas) e 0,7 (desigualdades muito grandes), com uma média de 0,4 .

Ele é construído com base nas informações de todos os Estados, salvo Cuba; e varia de .249 no Japão (Estado muito igualitário) a .578 na África do Sul (Estado muito desigual). Alguns coeficientes são acompanhados por um número: 4 para o Japão, 33 para a África do Sul. Este número é muito importante, pois exprime a relação entre as parcelas dos dois extremos:

- No Japão, as rendas dos $10 \%$ mais ricos são, em média, somente 4 vezes superiores às dos $10 \%$ mais pobres;

- Na África do Sul, a relação é de 1 a 33, o que explica a pobreza de uma grande parte da sua população.

O Japão, mais rico, atenua a pobreza; a África do Sul, menos rica, reforça-a ainda mais.

\footnotetext{
${ }^{21}$ Ele deve o seu nome ao estatístico, demógrafo e sociólogo italiano Corrado Gini (1884-1965). Este coeficiente foi descrito e utilizado nas duas obras anteriormente citadas (LANGOUËT, 2011 e 2014).
} 
Esta relação entre os decis nem sempre é indicada. Por isso apresentamos uma relação entre os quintis de renda (RQR), menos precisos, mas que permitem, por interpolação, uma estimativa da relação entre os decis ${ }^{22}$.

Dentre os Estados emergentes, o Brasil é desigual $(G=.539)$ : os $10 \%$ mais pobres recebem rendas 29 vezes inferiores a dos $10 \%$ mais ricos. Vem em seguida a China, na qual as desigualdades de rendas são medianas ( $G=.415)$, apresentando uma relação ainda elevada, 18. Mais próximos dos Estados igualitários, a Índia e a Rússia com coeficientes vizinhos (.325 e .310) permanecem na categoria mediana, e a relação entre os decis extremos resta mais elevada na Rússia (16) do que a relação estimada na Índia (12).

No grupo de controle, com o Japão anteriormente citado, aparece a Alemanha (.238, relação de 7), outro Estado muito desigual. O Canadá, com ligeira defasagem, e classificado como igualitário ( $G=.326$, relação estimada em 10 ), situa-se no nível da Rússia ou da Índia, mas com rendas para serem distribuídas claramente superiores às da Rússia e muito longe das da Índia. Enfim, aparece os Estados Unidos ( $G=.408$, relação de 16$)$, Estado classificado na posição mediana e em igualdade com a China.

Fora os Estados Unidos, os que informaram são menos numerosos que os Estados emergentes que continuam sofrendo o peso do seu passado, como a África do Sul, especialmente. Cuba não informou, mas seus resultados mostram no mínimo que sua população se beneficiou de redistribuições que permitiram certo nível de desenvolvimento nas áreas da saúde e da educação.

Enfim, e cada um pode verificar, as desigualdades de distribuição das rendas estão frequentemente em correlação com as desigualdades de gênero, mas também com as perdas de desenvolvimento humano que elas implicam.

\footnotetext{
${ }^{22}$ A interpolação é o cálculo de uma "4a proporcional". Tomemos o exemplo do Brasil em relação à África do Sul: a relação entre os decis é tal que $x / 33=17,6 / 20,2$, ou seja, 29. E assim por diante.
} 


\section{Para concluir}

Quer olhemos a União Europeia quer os Estados emergentes, as conclusões são quase idênticas: entre os Estados e no interior deles, o desenvolvimento humano é freado por desigualdades de todos os tipos e de todo gênero, que continuam aumentando ao invés de desaparecerem, numa corrida interminável aos lucros e ao crescimento insensato de um produto interno bruto que se torna um fim quando não é senão um meio.

As perdas de desenvolvimento humano constituem um desperdício inverossímil, especialmente nos países pobres como a Índia, mas também nos Estados emergentes como a África do Sul ou o Brasil, atingindo evidentemente as populações mais frágeis e mais desprovidas; e também, certamente, de modo mais atenuado, na primeira potência econômica mundial, os Estados Unidos.

A resposta é simples e pode ser lida em cada página: favorecer o desenvolvimento humano, aquele de todos os humanos, por meio da redução das desigualdades mais gritantes, de todas as desigualdades, e especialmente daquelas que reduzem parcelas inteiras de populações à precariedade e à extrema pobreza. Em todo lugar, as mídias nos lembram, a indignação brada entre os mais desprovidos e particularmente nos países emergentes; e a juventude se impacienta...

O conceito de desenvolvimento humano, desenvolvido por Amartya Sen e retomado no conjunto dos trabalhos do PNUD será, estou convencido disso, o conceito mais importante do século XXI. E é preciso que o seja, pois ele é uma resposta aos equívocos dos economistas liberais que ainda querem acreditar - ou nos fazer acreditar que o crescimento do PIB beneficia a todos, quando somente uma ínfima minoria é beneficiada, em detrimento de todos os outros e de um planeta pilhado, saqueado e seriamente ameaçado.

Essas desigualdades, que se justapõem e, sobretudo, se sobrepõem, atingem especialmente a educação, principal motor do desenvolvimento humano. Hoje, sem dúvida mais ainda do que no momento em que fora elaborada, há meio século, a teoria 
mais explicativa permanece a da herança cultural e da reprodução social de Pierre Bourdieu e Jean-Claude Passeron (1964 e 1970) ${ }^{23}$; e ela permanecerá assim enquanto as desigualdades continuarem fortes: hoje, em muitos casos, o fator "meritocrático", para retomar a terminologia de Raymond Boudon (1973), já não basta para inverter o peso do fator "dominância".

Mas as teorias não são eternas, ou elas seriam apenas dogmas. E elas são mais tenazes quando constituídas em bases sólidas: é o caso da teoria da reprodução; e ela será reforçada se as desigualdades aumentarem. Inversamente, ela enfraquecerá se as desigualdades recuarem: a reprodução social não é uma fatalidade, mas uma simples consequência da organização social.

São as desigualdades que se deve fazer recuar. É o "tudo pelo PIB" que é preciso ser revisto e considerado como um meio a ser mais bem controlado, e em hipótese alguma como um fim. A serviço de um objetivo essencial, o conceito de desenvolvimento humano ainda precisa, sem dúvida, ser aprofundado, e sua medida de progresso seria um indicador ao menos tão pertinente quanto o PIB. Exemplo disso, uma sociedade sem dúvida imperfeita, em que alguns dos seus Estados já estão mais próximos, é a Europa do Norte, mas também outras, dentre os antigos Estados socialistas. Uma sociedade na qual a educação, os saberes e as competências teriam, enfim, um verdadeiro lugar.

Junho de 2014.

\footnotetext{
${ }^{23}$ Les héritiers acaba de ser traduzido por dois colegas, amigo e amiga do Brasil. Parabenizo esta tradução que me parece muito exitosa (BOURDIEU e PASSERON, 2014).
} 


\section{Referências}

BOUDON, Raymond. L'inégalité des chances. Paris: Armand Colin, 1973.

BOURDIEU, Pierre ; PASSERON, Jean-Claude. La reproduction, éléments pour une théorie du système d'enseignement. Paris: Éditions de Minuit, 1970.

BOURDIEU, Pierre; PASSERON, Jean-Claude. Les héritiers : les étudiants et la culture. Paris: Ed. de Minuit, 1964.

BOURDIEU, Pierre ; PASSERON, Jean-Claude.Os herdeiros : os estudantes e a cultura. Florianópolis: Editora da UFSC, 2014.

LANGOUËT, Gabriel. Les inégalités entre États et populations de la planète, Trop, c'est trop !. Préface de Roger Establet.Paris: L'Harmattan, 2011.

LANGOUËT, Gabriel. Les inégalités dans l'Union européenne et ailleurs : et si on osait? Paris: L'Harmattan, 2014.

PNUD PROGRAMME DES NATIONS UNIES POUR LE DEVELOPPEMENT. Rapport sur le développement humain 2013l'essor du Sud: le progrès humain dans un monde diversifié. New York: PNUD, 2013. Disponível em:

<http://www.st.undp.org/content/dam/sao_tome_and_principe/docs/Rapport\%20STP/und P_st_HDR2013French.pdf>. Acesso em junho de 2014.

PNUD. PROGRAMME DES NATIONS UNIES POUR LE DEVELOPPEMENT. Rapport sur le développement humain 2011. Durabilité et Équité: un Meilleur Avenir pour Tous. New York: PNUD, 2011. Disponível em:

<http://hdr.undp.org/sites/default/files/hdr_2011_fr_complete.pdf >. Acesso em maio de 2014.

Recebido em: 11/06/2014 Aprovado em: 28/07/2014

Universidade do Estado de Santa Catarina - UDESC

Programa de Pós-Graduação em Educação - PPGE

Revista Linhas

Volume 15 - Número 29 - Ano 2014 revistalinhas@gmail.com 